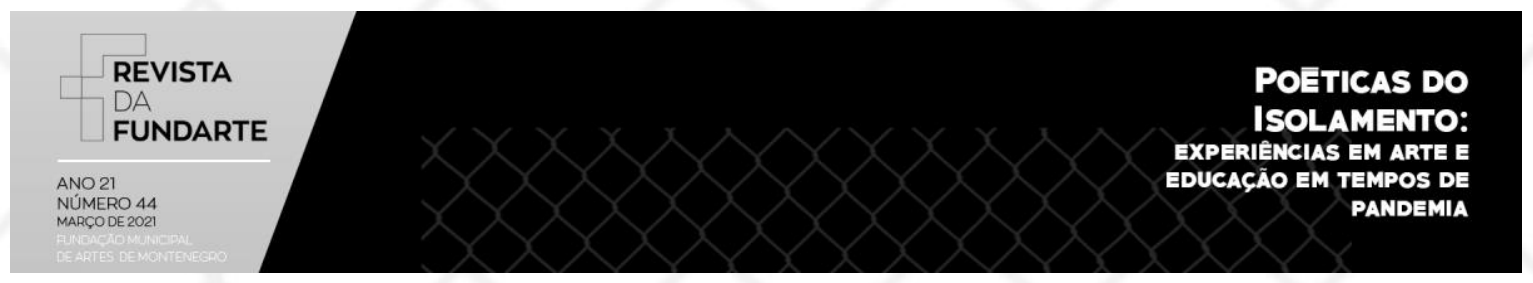

\title{
A MÁSCARA E A GATA: ARTE NA QUARENTENA DE UM PRÉ- ADOLESCENTE
}

Johannes Doll ${ }^{1}$

Cláudia Bechara Fröhlich²

Resumo: $O$ que a escola e as artes podem fazer nesta situação de distanciamento social e de ensino a distância? É desafiante para as e os professores e, muitas vezes, fica difícil ter uma noção dos efeitos na vida dos e das estudantes. O relato de produções artísticas de um menino de 11 anos, no 6o ano da escola, pode mostrar como elementos do ensino à distância podem provocar e inspirar o mundo imaginário de jovens. $O$ relato mostra, também, que as condições familiares, bem como a compreensão e a estimulação de caminhadas próprias, são fatores importantes para uma produção artística que contribua para o processo de subjetivação.

Palavras-chave: Adolescência;Processo de subjetivação;Produções artísticas.

\section{THE MASK AND THE CAT: ART IN THE QUARANTINE OF A PRETEEN}

Abstract: What can school and the arts do in this situation of social distance and distance learning? It is challenging for teachers and often difficult to get a sense of the effects on students and their lives. A description of artistic productions by an 11-year-old boy, 6th year at school, can show how elements of distance learning can provoke and inspire the imaginary world of young people. The report also shows that family conditions as well as the understanding and stimulation of own walks are important factors for an interesting artistic production.

Keywords: Adolescence; Subjectification process; Artistic productions.

Não sei por que me levaram para a casa da praia e eu não posso mais sair. Ouvi os adultos falarem que estamos em quarentena de um tal COVID-19. Eu gosto daqui porque tem um pátio grande e gosto de dormir, fazer arte, mais arte e dormir mais... (Artur, crônica 1)

\section{Introdução}

A pandemia da Covid-19 pegou todos de surpresa, mudou profundamente a forma de vida, de estudo, de trabalho. Para crianças e jovens, o estudo passou a ser

\footnotetext{
1 Teólogo, pedagogo, gerontólogo, Mestre em Educação (UFRGS), doutor em filosofia (Universidade de Koblenz-Landau, Alemanha), professor titular da Faculdade de Educação da UFRGS

2 Possui graduação em Psicologia pela Universidade Federal do Rio Grande do Sul (1997), mestrado (2009) e doutorado (2014) em Educação pela Universidade Federal do Rio Grande do Sul. Realizou Pós Doutorado vinculado ao Pós-Graduação em Psicanálise: Clínica e Cultura na Universidade Federal do Rio Grande do Sul (2016). Professora do Departamento de Estudos Básicos da Faculdade de Educação da Universidade Federal do Rio Grande do Sul.
}

DOLL, Johannes; FRÖHLICH, Cláudia Bechara. A máscara e a gata: arte na quarentena de um préadolescente. Revista da FUNDARTE. Montenegro, p.01-18, ano 21, no 44, janeiro/março de 2021.

Disponível em: http://.seer.fundarte.rs.gov.br/index.php/revistadafundarte/index> 30 de março de 2021. 


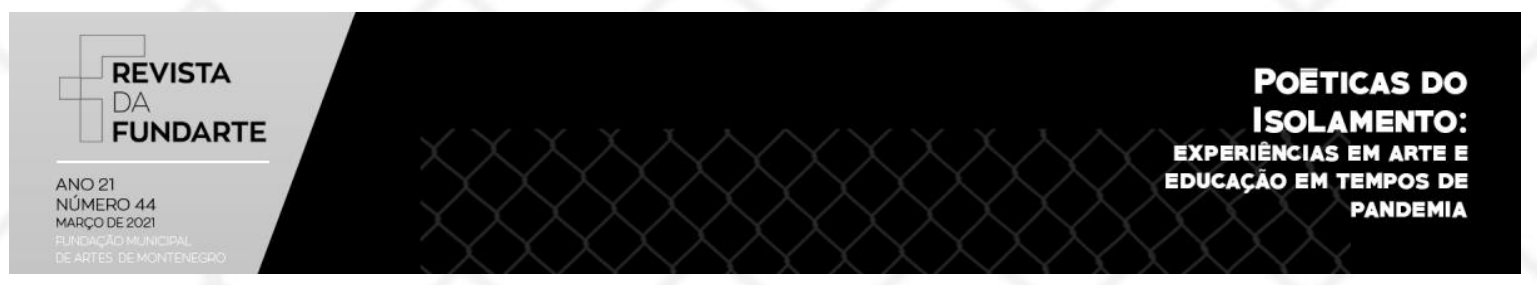

à distância, o isolamento social restringiu os contatos diretos ao contexto da família ou daqueles que habitam juntos o mesmo espaço. As condições específicas desse acontecimento histórico provocaram solidão, depressão, medo, revolta, mas criaram também processos de adaptação, de resiliência, de criatividade. Assim, o presente artigo mostra, ao ler/olhar a produção artística de um menino de 11 anos, de que modo o suporte de professores e familiares - diante da passagem da infância para a juventude de um pré-adolescente - pode levar a produções artísticas que permitem expressar e elaborar as experiências singulares dessa situação histórica. Um olhar aberto e uma leitura atenta dessas produções artísticas e suas condições de construção permitem a docentes e pais uma compreensão da relevância dessas produções no processo de subjetivação.

\section{A história de Artur: um quase estudo de caso}

Quase memória: quase romance, a ficção de Carlos Heitor Cony (1995), emprestou um modo de apresentarmos Artur: como um quase estudo de caso. No romance de Cony, o gesto de abrir um embrulho dispara no personagem recordações de sua infância com sua família. Os capítulos do livro são as memórias dessas relações. No caso deste artigo, ao lermos as Crônicas de uma gata em quarentena, escritos de Artur, de 11 anos, surgiu nos autores o desejo de escrever sobre as relações escola-família-quarentena e o lugar da arte para um adolescente em isolamento social.

Vamos chamá-lo de Artur, ${ }^{3}$ um pré-adolescente de 11 anos que frequentou o sexto ano em uma escola particular. Depois do retorno à escola, em fevereiro de 2020, a pandemia impactou na vida da família. A escola fechou e depois voltou com um ensino à distância, inicialmente por meio de tarefas encaminhadas pelos professores, depois em uma forma mista de aulas síncronas e tarefas assíncronas. A família, por precaução, se mudou para sua casa de praia, tendo em vista a saúde

\footnotetext{
3 Tanto Artur, nome fictício, quanto seus pais foram informados sobre o estudo/leitura das produções
} artísticas do menino pelos autores do artigo e concordaram com a publicação.

DOLL, Johannes; FRÖHLICH, Cláudia Bechara. A máscara e a gata: arte na quarentena de um préadolescente. Revista da FUNDARTE. Montenegro, p.01-18, ano 21, no 44, janeiro/março de 2021.

Disponível em: http://.seer.fundarte.rs.gov.br/index.php/revistadafundarte/index> 30 de março de 2021. 


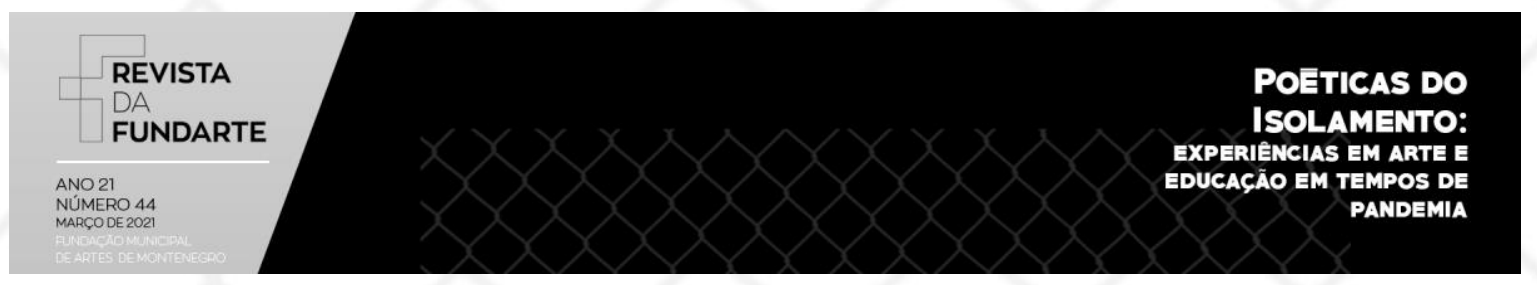

da avó em idade avançada e da mãe com problemas pulmonares. Desde março de 2020, Artur vive nessa casa com pátio e muro ao redor, junto com seu irmão, seus pais, sua avó e sua gata. Durante esse ano, Artur ensaiou-se em diversas formas de atividades/produções no campo das artes e que serão tomadas neste artigo como diferentes modos de escrever sua história de quarentena. Já antes praticou fabricar objetos do seu mundo com papelão, cola, fita e outros materiais. Essa produção ficou mais intensa durante o ano e abrangeu máscaras, armas de vários tipos, jogos eletrônicos etc. A segunda linha de produção na quarentena constitui-se de trabalhos em argila. Com a possibilidade de trabalhar ao ar livre e com menos restrições em relação à sujeira, ele criou figuras que foram pintadas. $O$ terceiro campo que Artur descobriu nesse ano foi a escrita de crônicas. A partir de um tema de casa em que deveria terminar uma crônica com dois cachorros, ele se lembrou da sua gata e começou a escrever pequenas histórias sobre a vida em quarentena a partir da perspectiva dela. Estimulado pela professora e pela mãe, Artur seguiu escrevendo muitas crônicas.

Há diferentes formas de olhar/ver/ler produções artísticas, e esta abertura de olhares apontam a riqueza da relação humana com a arte. Para além das produções de Artur, que incluem temas relativos à adolescência e elementos da pandemia, sublinhamos a importância de a escola e a família não recuarem diante dessas produções, reconhecendo nelas tentativas de Artur de se subjetivar nesse contexto, de encontrar, pelo exercício de dar forma/materialidade às palavras, um modo de seguir sua jornada subjetiva rumo ao mundo adulto e de encontrar um lugar simbólico para si no meio da crise instaurada.

A trama tecida por Artur, e desenrolada por diferentes materialidades (esculturas, figuras, crônicas), constitui o material do nosso quase estudo de caso, um artifício metodológico que ora situamos no campo da invenção/ficção. O quase estudo tem a marca da incompletude e do provisório, justamente porque a história de Artur segue se desdobrando em ainda outros tempos, e nem tudo será contado. Também tem a marca da invenção porque, a cada história que se conta, aumenta-se adolescente. Revista da FUNDARTE. Montenegro, p.01-18, ano 21, № 44, janeiro/março de 2021.

Disponível em: http://.seer.fundarte.rs.gov.br/index.php/revistadafundarte/index> 30 de março de 2021. 


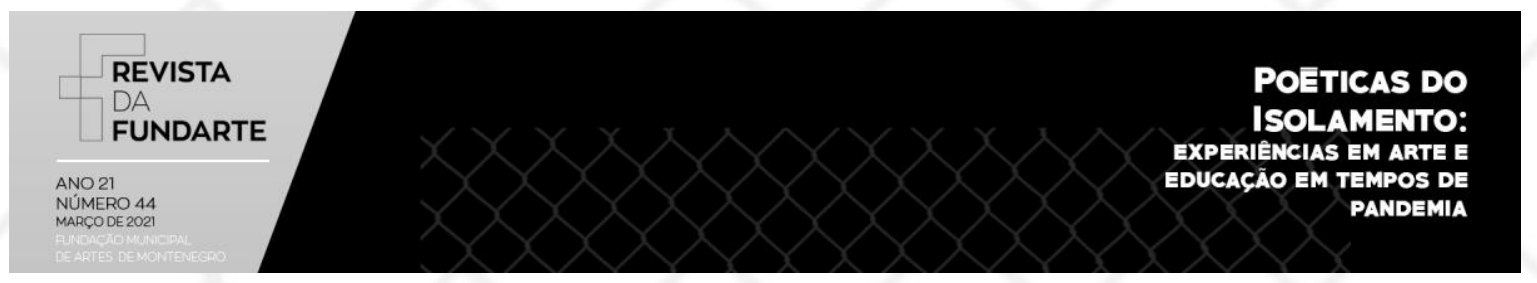

um ponto, inserindo a história de Artur numa verdade que, parafraseando Lacan ([1959-1960] 1997), tem para nós estrutura de ficção. E mesmo com esses predicados, o quase estudo parece permitir que a articulação entre arte, educação e psicanálise ofereça aos docentes em tempos de pandemia algumas perspectivas de retomada do ensino.

\section{Processo de subjetivação e produção artística}

A adolescência é um extenso espaço de tempo no qual ocorrem o desligamento gradual da infância e a propagação para a vida adulta. É tempo de partir, de perder de vista a história dos pais e inventar um rumo para si na vida (CORSO; CORSO, 2018). Nesse tempo de transição, o adolescente carrega os elementos da sua infância (palavras, histórias, fotografias etc.) e com eles tenta se reinventar. É como se esses elementos servissem de matéria-prima com a qual precisará construir, alicerçar seu futuro. Entretanto, esses restos da infância em forma de palavras e/ou sons, que na parceria da psicanálise chamaremos de "significantes", 4 precisam entrar num jogo de alteridade, precisam ser colocados à prova diante dos amigos, dos colegas da escola, para se rearranjarem. Nessa perspectiva, o sujeito é construído de linguagem e emerge enquanto tal como efeito das palavras que escutou sobre si. Muito do que se escuta é marcado como tatuagem no corpo e, muitas vezes, aloja-se num recanto de si e que Freud chamou de inconsciente. O curioso é que nenhum adulto tem o poder de controlar quais as marcas serão feitas, tampouco seus efeitos. É na adolescência, quando se abre esse tempo de passagem, que as marcas-tatuagens de linguagem, os significantes, reviram-se em busca de outras significações, como se o sujeito em trânsito para o

\footnotetext{
4 Um significante é algo que se repete na passagem de geração para outra geração. Ele não é propriedade privada de nenhuma família, embora nela reapareça com diferentes significados; ele cruza, circula, atravessa gerações, perpassa o individual, o social (RODULFO, 1990). A palavra "máscara", por sua força de repetição nesse momento da vida de Artur, irá reaparecer em sua produção artística, como forma de, resguardando sua polissemia, manter em aberto a possibilidade de ressignificação.
}

DOLL, Johannes; FRÖHLICH, Cláudia Bechara. A máscara e a gata: arte na quarentena de um préadolescente. Revista da FUNDARTE. Montenegro, p.01-18, ano 21, № 44, janeiro/março de 2021.

Disponível em: http://.seer.fundarte.rs.gov.br/index.php/revistadafundarte/index> 30 de março de 2021. 


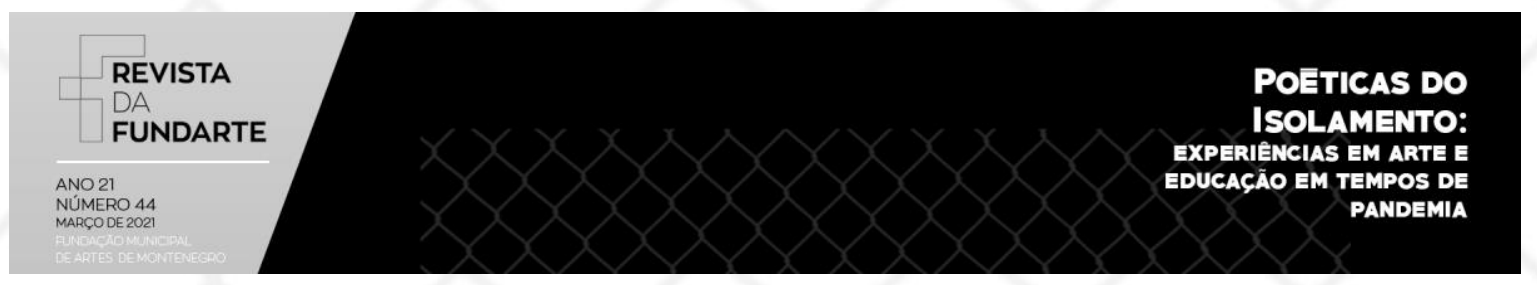

mundo adulto precisasse encontrar novas versões para si, outros modos de se contar; maneiras que não sejam a mesma narrada pelos pais, avós e professores da infância.

Vivemos numa sociedade que cultua a adolescência (CORSO; CORSO, 2018), e essa mensagem está estampada nas produções de nossa cultura (filmes, séries, gibis, games etc.). Há, nelas, uma promessa de que quando esse tempo chegar para o adolescente, o espaço da rua - para além dos muros da casa - Ihe aguarda, cheio de aventuras a serem vividas com os pares. Os adultos, que recebem suas crianças na polis, lembram constantemente: "aproveita que passa depressa!"; tatuam também com a marca da linguagem, a expectativa de que esse espaço/tempo não deveria ser breve.

Com o isolamento social, iniciados no Brasil em março de 2020, esse tempo/espaço quase mágico e prometido poucos meses antes, para muitos préadolescentes, não aconteceu fora do ambiente familiar, nem na urgência de um tempo que passa depressa. $\mathrm{E}$ pior, havia uma expectativa de que $\mathrm{o}$ isolamento durasse apenas alguns meses e, em seguida, tudo se reestabeleceria como antes. Porém, passado um ano, a realidade brasileira é de incerteza quanto à volta presencial às aulas no próximo ano letivo. Com a pandemia, uma série de problemas e impasses se colocou entre os muros da escola, escancarando o abismo entre o ensino público e o ensino privado. Entre as escolas privadas, foi possível uma organização de aulas online, de início por meio de metodologias que transpunham - sem muito sucesso - o modelo presencial para o EAD e, em seguida, encontrando, pela via da invenção e muitas gambiarras pedagógicas, outros modos de habitar o espaço virtual e fazer o convite para as aprendizagens. Artur, por estar matriculado numa escola privada, teve a oportunidade de dar seguimento à distância e, por contingência do trabalho dos pais e necessidade de proteger a família do coronavírus, pôde realizar o período de isolamento num local distante da capital, numa região de litoral. Preso à casa, circunscrito aos muros de seu quintal, numa estranha temporalidade que fazia o tempo não passar, e num adolescente. Revista da FUNDARTE. Montenegro, p.01-18, ano 21, o 44, janeiro/março de 2021.

Disponível em: http://.seer.fundarte.rs.gov.br/index.php/revistadafundarte/index> 30 de março de 2021. 


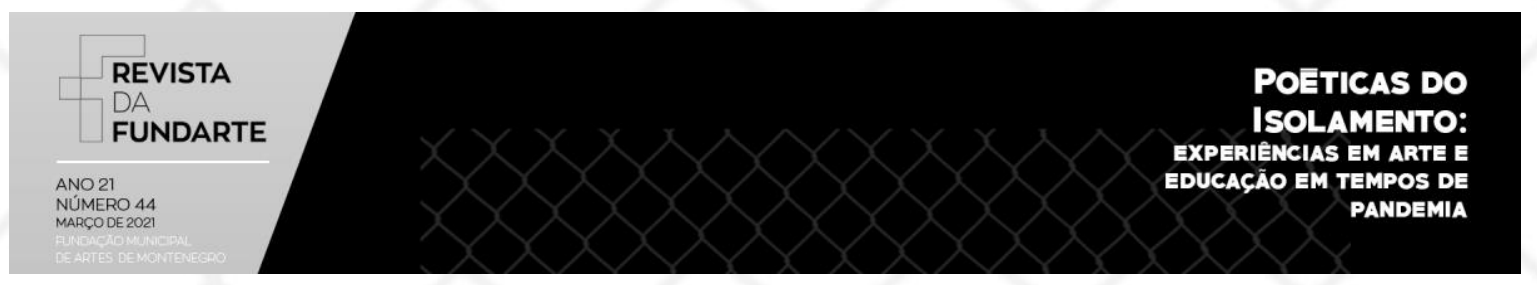

litoral (quase limbo) entre a infância e a adolescência, Artur precisou encontrar modos de fazer o jogo da alteridade, o estar-com seus pares ao mesmo tempo que revisitava as marcas de linguagem que o reconheciam como Artur para o mundo. $O$ que o significante "Artur" significava para ele e para seus pares? Com materiais como cola, tesoura, argila, papelão, tinta etc., materiais que são comuns à escola, Artur colocou literalmente a mão na massa, e ergueu alguns objetos artísticos, modelando a realidade conforme os limites do terreno lhe davam condições. Assim, destacamos a importância de Artur ter encontrado nos pais e na escola condições de possibilidade para, por meio da arte, construir-se na estrada - dura e tensa - da adolescência, dar seguimento a seu processo de subjetivação em meio ao exílio da pandemia. O que esses adultos possibilitaram foi, ao invés de colar a aprendizagem formal da escola a tarefas repetitivas e sem sentido para ele, um ir além de seus limites, mantendo acesa a dimensão lúdica, o campo do brincar, do sujar-se, do transbordar os limites do instituído e, principalmente, da dimensão significante de suas marcas de linguagem-tatuagens; elementos que a arte também conjuga, ${ }^{5}$ possibilitando, assim, por meio das construções ficcionais, franquear as passagens difíceis da subjetivação adolescente.

Fazer arte tem um duplo sentido na língua portuguesa, é o momento em que os jovens transbordam os limites definido pelo adulto e, ao mesmo tempo, refere-se à criação artística. Enquanto fazem arte, as crianças e os adolescentes estão armando suas bordas corporais, carimbando com sua marca o objeto, colocando sua assinatura numa versão de si; estão elaborando as perdas que o crescer the impõe. O jogo é fazer fundamental para estabelecer os laços numa cultura; é o motor da própria cultura, mola propulsora da vida, e mesmo que solitário, inclui o outro (HUIZINGA, [1938] 2000). Em português, o termo brincar, tem relação com a

\footnotetext{
${ }^{5}$ Há vários pontos de contato entre a arte e a psicanálise: o inconsciente, $\mathrm{o}$ ato analítico, a função do objeto a, as dimensões do simbólico e do imaginário no fazer artístico, a obra de arte como passagem da posição de fetiche para a posição de falta, o lugar da transgressão, a instância do traumático que a arte consegue colocar em cena (MARSILLAC, 2018). Buscamos aproximar os dois campos no sentido de que arte e psicanálise convidam a dar contornos ao vazio, ao indizível, ao impossível de se alcançar com as palavras.
} adolescente. Revista da FUNDARTE. Montenegro, p.01-18, ano 21, o 44, janeiro/março de 2021.

Disponível em: http://.seer.fundarte.rs.gov.br/index.php/revistadafundarte/index> 30 de março de 2021. 


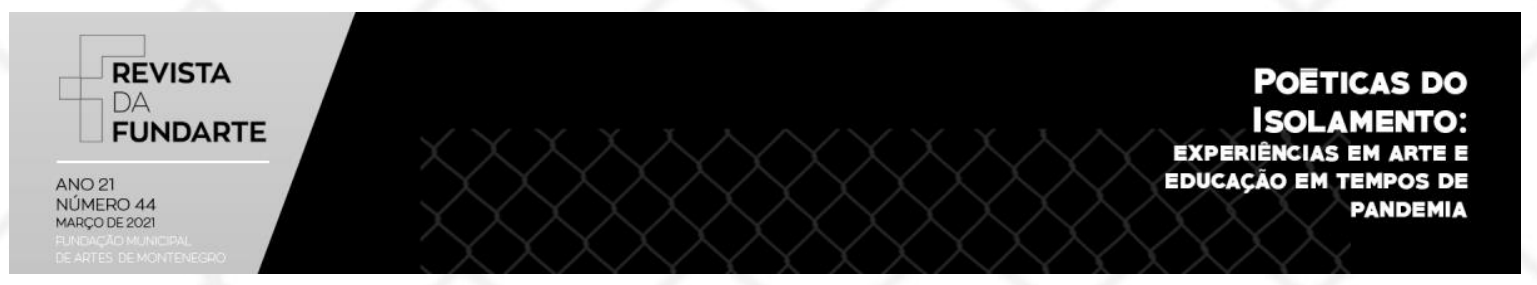

palavra vinculum, do latim, significando laço ou união, ressaltando essa ideia da dimensão do outro, de jogo e alteridade (SANTA ROZA, 1993). Inicialmente a palavra latina ludus relacionava-se à escola, que significava "ócio" e divertimento, e foi mais tarde que adquiriu o sentido oposto, o de exercício sistemático. À medida que se foi restringindo a liberdade que as crianças tinham de dispor de seu tempo/espaço, a ideia de escola também foi se afastando de ócio. Nesse tempo de isolamento, cabe às escolas e às famílias se perguntarem por diferentes maneiras de convidar os jovens a retomarem o tempo dedicado ao ócio, ao livre criar a partir dos significantes, da matéria-prima que constrói um sujeito.

Para Freud ([1908] 1976), os primeiros vestígios do trabalho de elaboração poética estão na infância, e mais adiante os encontramos, de outro modo, no adulto que escreve. Tanto a criança que brinca/joga quanto o escritor criativo entregam-se a um mesmo fazer: reajustam os elementos (palavras, imagens, sons) de seu mundo de uma nova forma. Quando a criança, aparentemente, para de brincar, e cresce, substitui essa atividade por outra, o fantasiar, em que passa a "construir castelos no ar" e cria devaneios, sonhos em plena luz do dia. O escritor criativo é esse que faz arte com linguagem, que retira as palavras da submissão prática do cotidiano e que ergue, a partir de suas fantasias, formas de narrar, reajustando seu texto para que fisgue um leitor, um olhar atento.

Artur dá a ver o que construiu no isolamento social, quer que suas produções artísticas encontrem o olhar do outro; autoriza que se registre, nos anais da vida, sua vivência de quarentena. Desse modo, perguntamo-nos, ajudados pelo nosso quase estudo de caso, de que maneira a escola e a família podem ler/olhar a produção de um adolescente? Se as produções ficcionais são construídas a partir da linguagem, num jogo de alteridade, elas se perfazem num entre realidade interna e externa, entre consciente e inconsciente, com elementos da noite e do dia, do que se vê pela janela, na TV, daquilo que se escuta dentro de casa, ou seja, não é somente uma expressão de si. Desse modo, o adulto talvez devesse abandonar uma posição de leitura que intente um furor interpretantis, que busque encontrar adolescente. Revista da FUNDARTE. Montenegro, p.01-18, ano 21, no 44, janeiro/março de 2021.

Disponível em: http://.seer.fundarte.rs.gov.br/index.php/revistadafundarte/index> 30 de março de 2021. 


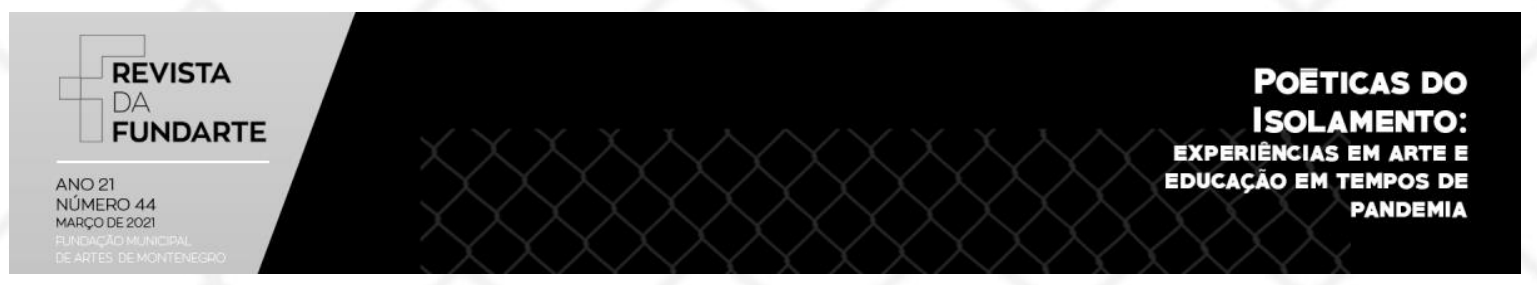

significados a cada elemento encontrado na obra/no texto, para assumir uma posição de leitura de modo a acolher um fazer artístico que se dá a ver, uma obra que quer dizer algo, mas que ainda não sabe o quê. É preciso tomar as produções como uma abertura para uma conversa e, talvez, por meio dela certos elementos da produção do jovem adquiram algum efeito de sentido, embora momentâneo. $O$ sujeito é descentrado da consciência; sujeito e sentido não existem, revelam-se no plano da linguagem, produzem-se no trabalho discursivo, no jogo da alteridade que o dizer da produção encaminha. Muitas vezes, as preocupações com os jovens dizem mais sobre os adultos do que sobre os jovens (CORSO; CORSO, 2018); então, é preciso, antes, fazer as pazes com a própria adolescência - com o tempo em que um dia se habitou - e lembrar de como se mantém aberto esse canal com o campo do lúdico. O adulto funciona como um agente de saber, como aquele que, por ter mais recursos de dizer, sabe (SANTA ROZA, 1993); mas, para esse acolhimento, poderia se manter na posição de guardião da provisoriedade do significado das palavras, manter vivo o jogo polissêmico do dizer e poderia saber menos sobre o que o jovem quer dizer com a obra que carrega em mãos e mais sobre descobrir diferentes maneiras de incentivar que ele siga produzindo.

Após um período esculpindo objetos de quarentena, e encontrando o olhar e a disponibilidade lúdica dos adultos ao seu redor, Artur se aventura a escrever crônicas, alterando o campo empírico onde faz seu jogo de linguagem. A leitura de Crônicas de uma gata em quarentena é um convite ao adulto a revisitar seu próprio tempo de passagem da infância para a adolescência. Nas crônicas, encontra-se Artur numa outra intimidade com as palavras, num ensaio de mestria em fisgar o leitor pelo fio de seu dizer.

\section{Fazendo arte na pandemia: da máscara à crônica}

Vamos dar uma olhada mais de perto nas produções do Artur. Realizar trabalhos em materiais de fácil manuseio e de materiais reciclados é hoje comum no 


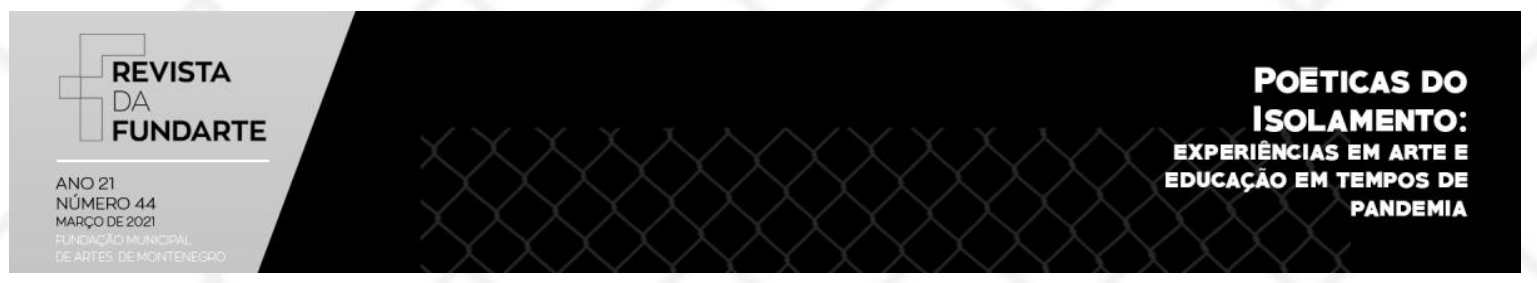

trabalho escolar, principalmente na educação infantil e nas séries iniciais. A partir de vivências anteriores, Artur (re)constrói experiências, desejos (novo videogame) e desenvolve várias versões de um dos objetos mais antigos e arcaicos da humanidade: a máscara. Seguem algumas reflexões a respeito de três máscaras elaboradas por Artur.

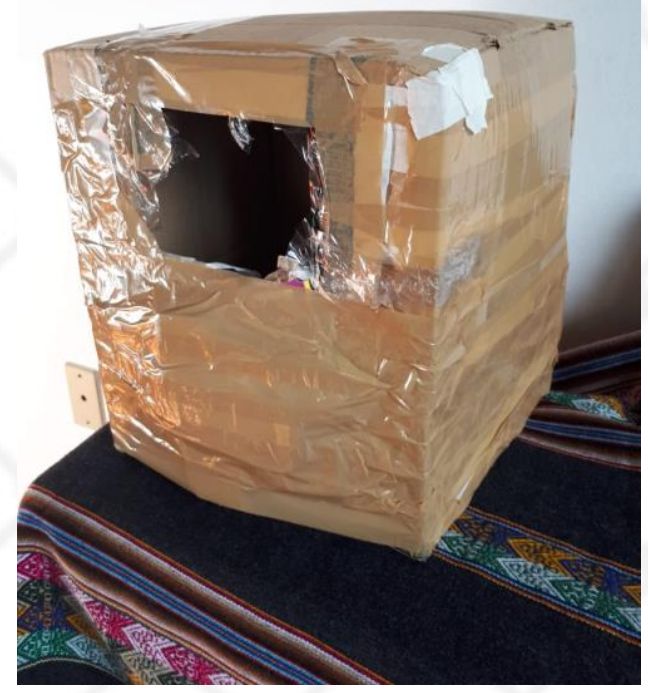

Figura 1 - Máscara capacete (Fonte: autores)

O primeiro modelo é uma caixa, onde foi aberto um visor, tapado de plástico. Abaixo do visor se encontra uma pequena elevação, representando o filtro. Esse tipo de máscara tem a função de proteção, principalmente em ambientes hostis como no espaço, em explorações submarinas, na guerra... Fica muito fácil de criar relações com a situação atual, em que a máscara, mesmo em outras dimensões, tornou-se imprescindível. Cada vez que se sai do ambiente protegido da casa ou do apartamento, é necessário colocar. A forma grande de envolver a cabeça inteira remete a um capacete. Dentro do capacete, a cabeça fica praticamente invisível, o que pode também proteger de olhares curiosos e hostis, como mostra o livro (e adolescente. Revista da FUNDARTE. Montenegro, p.01-18, ano 21, no 44, janeiro/março de 2021.

Disponível em: http://.seer.fundarte.rs.gov.br/index.php/revistadafundarte/index> 30 de março de 2021. 


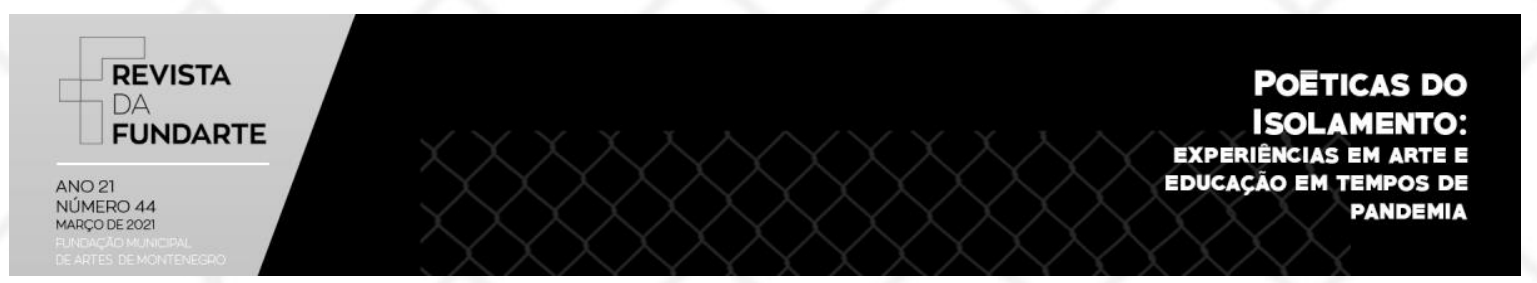

filme) Extraordinário, escrito por Raquel J. Palacio, em que Auggie, um menino com uma severa deformidade facial, usa durante certo tempo um capacete para se proteger dos olhares e comentários de outras pessoas. Esse livro foi lido nas aulas de português, no $6^{\circ}$ ano.

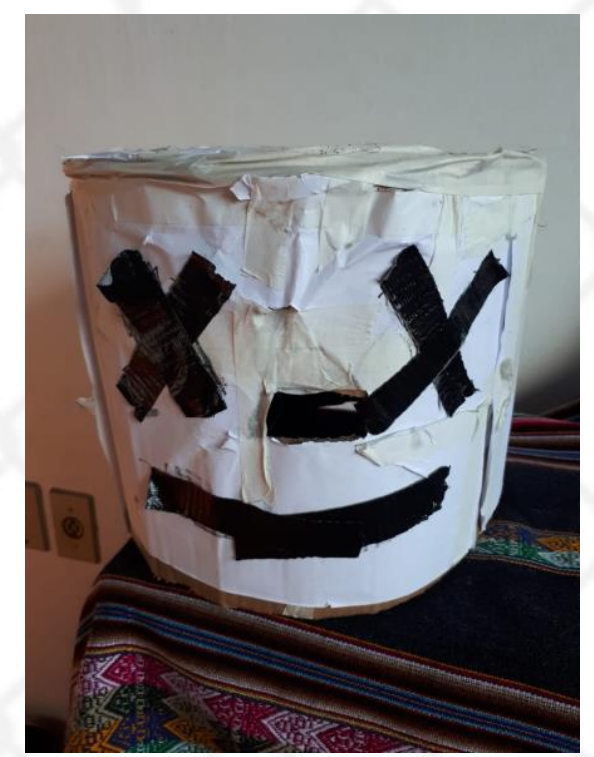

Figura 2 - Máscara palhaço (Fonte: autores)

O segundo modelo traz outro uso para a máscara: assumir uma outra identidade. Um dos temas centrais do carnaval, a máscara permite, durante certo tempo, entrar no papel de uma outra personagem; num ensaio sobre o outro. Com ela, pode-se escapar, temporariamente, de expectativas sociais que orientam, mas também limitam o comportamento. Na nossa perspectiva, os sujeitos possuem uma variedade de personas; assim, a máscara na função de disfarce ou de ensaio de ser um outro, pode contribuir para viver experiências e comportamentos que transbordem o instituído. O jogo de ser outro, de experimentar novos papéis, é fundamental no processo de subjetivação.

Nesse caso, Artur escolheu a máscara de um palhaço. Escolha interessante, pois o papel do palhaço é ambíguo. Vindo de uma longa tradição de figuras engraçadas no teatro grego e romano, o palhaço normalmente é visto como uma adolescente. Revista da FUNDARTE. Montenegro, p.01-18, ano 21, no 44, janeiro/março de 2021.

Disponível em: http://.seer.fundarte.rs.gov.br/index.php/revistadafundarte/index> 30 de março de 2021. 


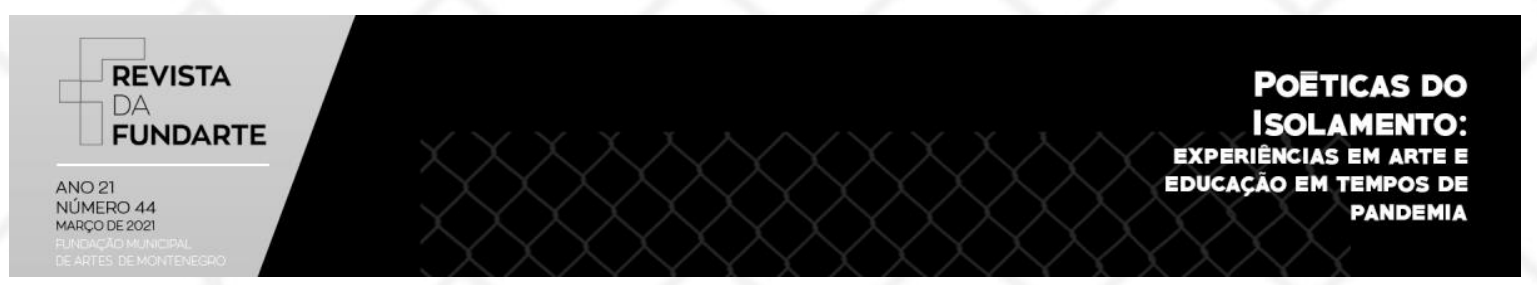

figura divertida. Mas a figura do palhaço atual, e que povoa o imaginário de Artur, possui uma série de contradições, como o riso forçado que esconde os sentimentos e intenções, a maquiagem exagerada que torna o rosto do palhaço menos humano e a imprevisibilidade do seu comportamento. Desde o surgimento do "palhaço malvado", como no livro e filme It, de Stephan King (1986), o palhaço ganhou na cultura popular tantos elementos de terror, que um estudo de 2016 nos Estados Unidos mostrou que os norte-americanos sentem mais medo do palhaço do que de ataques terroristas. ${ }^{6}$

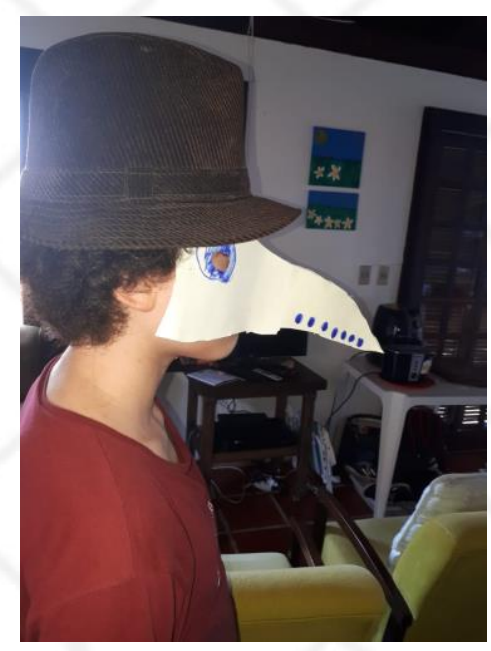

Figura 3 - Máscara do médico da peste (Fonte: autores)

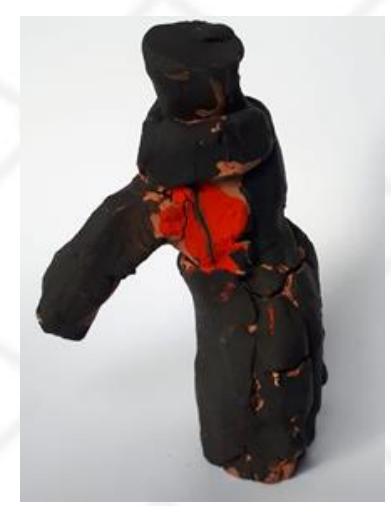

Figura 4 - Médico da peste - argila (Fonte: autores)

\footnotetext{
${ }^{6}$ Ver em: <https://www.britannica.com/story/why-are-people-afraid-of-clowns >. Acesso em: 2 fev. 2021.
}

DOLL, Johannes; FRÖHLICH, Cláudia Bechara. A máscara e a gata: arte na quarentena de um préadolescente. Revista da FUNDARTE. Montenegro, p.01-18, ano 21, no 44, janeiro/março de 2021.

Disponível em: http://.seer.fundarte.rs.gov.br/index.php/revistadafundarte/index> 30 de março de 2021. 


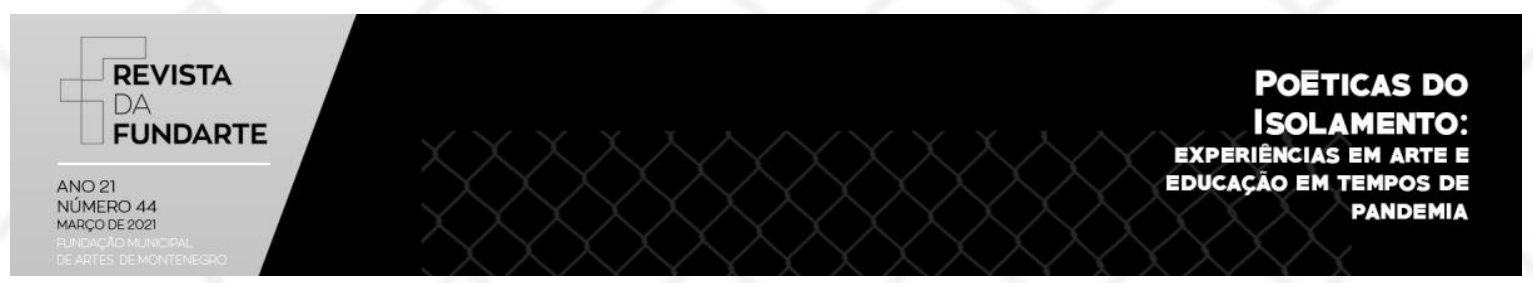

O terceiro modelo de máscara construído por Artur, com um nariz enorme que parece o bico de um pássaro, traz uma referência histórica à vivência de uma pandemia: as epidemias da peste bubônica. Usada pelos médicos que tratavam os doentes da peste, o bico longo servia para colocar ervas ou aromatizantes que deveriam proteger contra a infecção. Apesar de ser encontrada somente na França e na Itália do século XVII (RUISINGER, 2020), a imagem entrou fortemente no imaginário popular, também pela retomada desse tipo de máscara no Carneval de Venécia.

O tema dessa máscara impressionou Artur, que se dedicou em sua construção, assim como se empenhou na modelagem das figuras de argila, nas quais o homem com nariz enorme retorna. Não é somente uma máscara histórica de proteção, mas é algo que é vinculado a ameaças fortes e até mortais, como a peste. Nessa perspectiva, a máscara da peste assume uma nova função - a de assustar, de espantar. O interessante é que esse elemento do feio, do grotesco, do afastar, encontra-se também nas máscaras tradicionais do Carneval Alemannic (EISERMANN, 1991).

Atentos às máscaras construídas por Artur durante a pandemia, e ao deslizamento significante que as acompanha, percebemos uma série de funções que elas podem assumir nesta situação: máscara-capacete, máscara-carnaval, máscara-peste. A abrangência vai desde uma conotação histórica que relaciona a situação da pandemia a experiências humanas de séculos anteriores, tematiza doença e ameaça da morte, mostra a vontade de proteção e aponta para o desejo de experimentar com ambivalências.

O docente atento, que mantém um olhar sensível às produções, consegue perceber os rastros das suas aulas, e de que forma estudantes podem ir além a partir de pistas/palavras que surgem nas aulas. Nas máscaras de Artur, encontramse elementos que podem ter vindo das aulas de História (pandemias no passado), das aulas de Português (leitura do livro Extraordinário) ou também das aulas de Arte adolescente. Revista da FUNDARTE. Montenegro, p.01-18, ano 21, no 44, janeiro/março de 2021.

Disponível em: http://.seer.fundarte.rs.gov.br/index.php/revistadafundarte/index> 30 de março de 2021. 


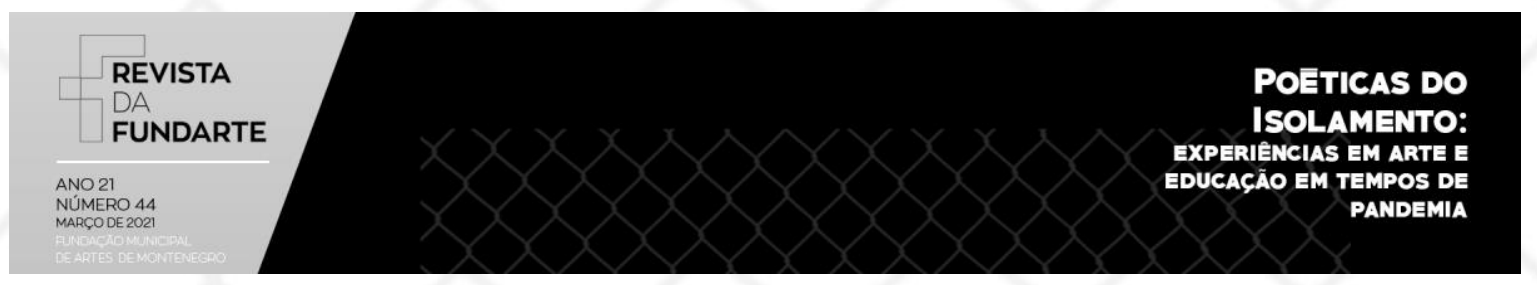

(máscaras africanas); elementos que sustentaram a malha simbólica envolvida nessas produções.

Trabalhar com argila possui em comum com fazer máscaras o fato de que se trabalha com um determinado material para criar algo novo, ambos no nível do concreto. O diferente é que a máscara geralmente tem uma função e que ela se mantém próxima ao corpo, quase como um acessório, e precisa se adequar ao rosto. Já formar figuras com argila libera do caráter funcional e possibilita criações novas. Assim, Artur descobriu o gosto de trabalhar com argila durante a pandemia e encontrou condições adequadas para se dedicar a isso. Surgiu durante o ano uma série de figuras, algumas mostradas a seguir:

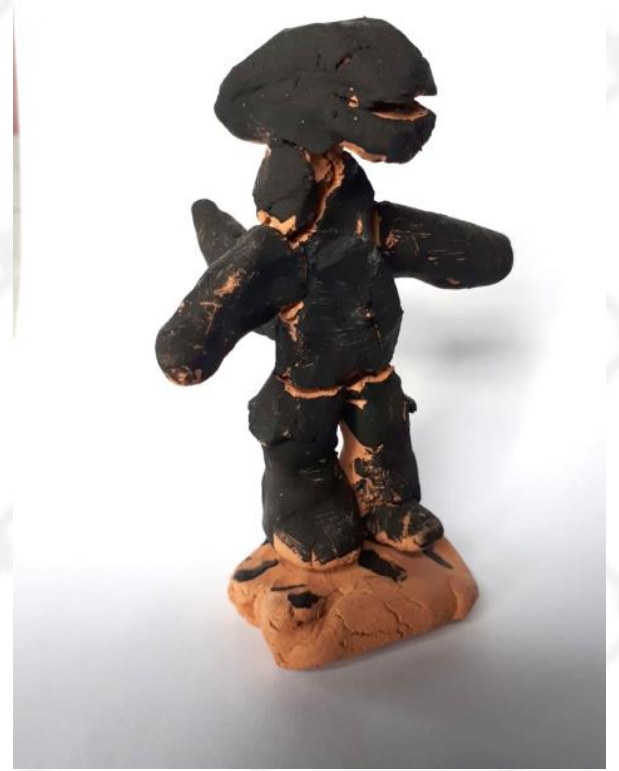

Figura 5 - Alien (Fonte: autores)

Formar figuras com argila é um processo criativo em que ideias, pensamentos e imaginações ganham concretude, ingressam numa materialidade que pode ser vista, tocada, enfrentada. No momento em que essas figuras se tornam material, é possível enfrentá-las, distanciar-se delas, compreender. Em alemão, a palavra begreifen (compreender) é baseada na palavra greifen (pegar): quando posso pegar 


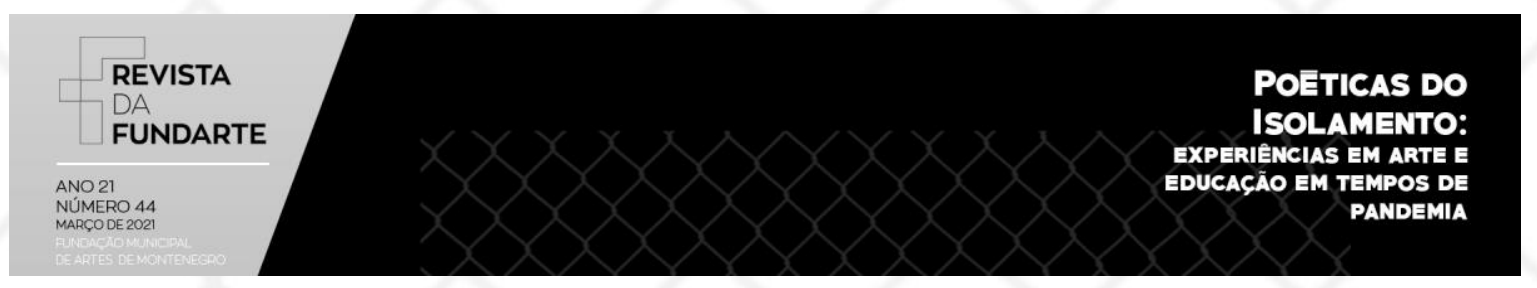

na coisa, posso compreendê-la. Olhando por esse lado, percebe-se nas figuras feitas por Artur elementos escuros, ameaçadores, como na figura do alien no filme Alien, o oitavo passageiro, dirigido por Ridley Scott (1979). No filme, o alien usa o corpo humano para se hospedar e sai do corpo matando o hospedeiro. Não se sabe até que ponto Artur conhece toda a história de modo consciente, mas a figura escura, ameaçadora ganha nas mãos dele corpo, proporções e cores, sendo possível de ser abordada. Certamente uma forma interessante de enfrentar os medos que muitas crianças nessa idade sentem.

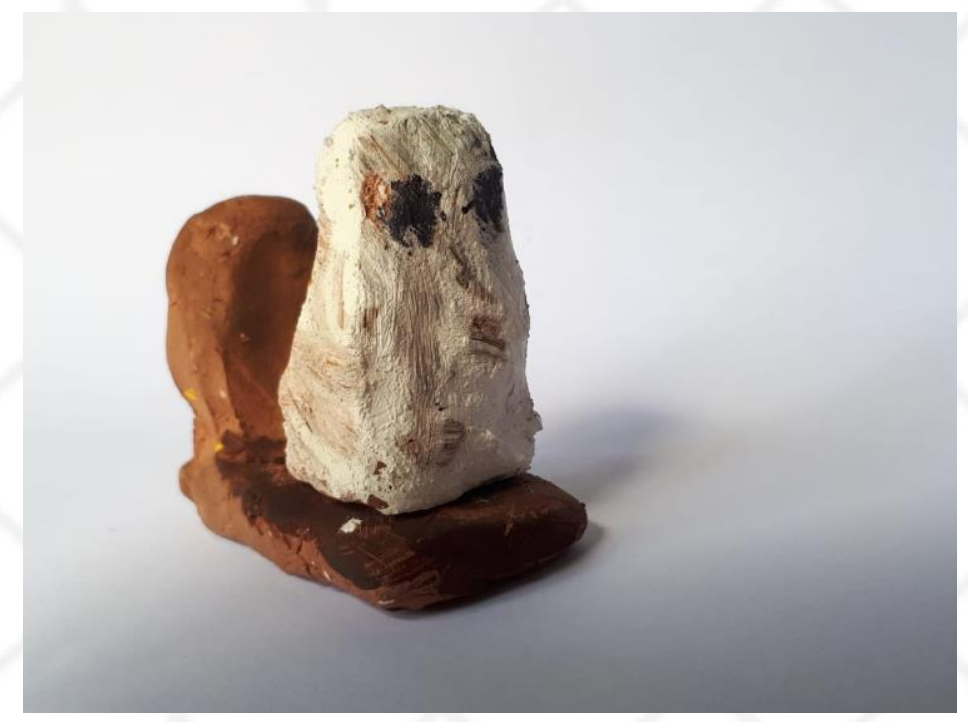

Figura 6 - O fantasma (Fonte: autores)

A segunda figura é um fantasma que está saindo do túmulo. De novo aparece um medo clássico, a questão da morte e do desconhecido que volta para assustar os vivos. Mas ao contrário do alien, o fantasma não possui o aspecto assustador. É algo que, depois de morto e enterrado, volta à presença. Não possui uma figura clara, determinada; é vago. Não se sabe quais são os fantasmas de Artur, talvez ele mesmo não saiba. Mas, de novo, na forma de argila, o fantasma cujo poder vem exatamente do vago, do não definido, de uma sensação estranha, ganha corpo e materialidade. E nesse momento, quando se torna possível pegar, tocar, o fantasma adolescente. Revista da FUNDARTE. Montenegro, p.01-18, ano 21, no 44, janeiro/março de 2021.

Disponível em: http://.seer.fundarte.rs.gov.br/index.php/revistadafundarte/index> 30 de março de 2021. 


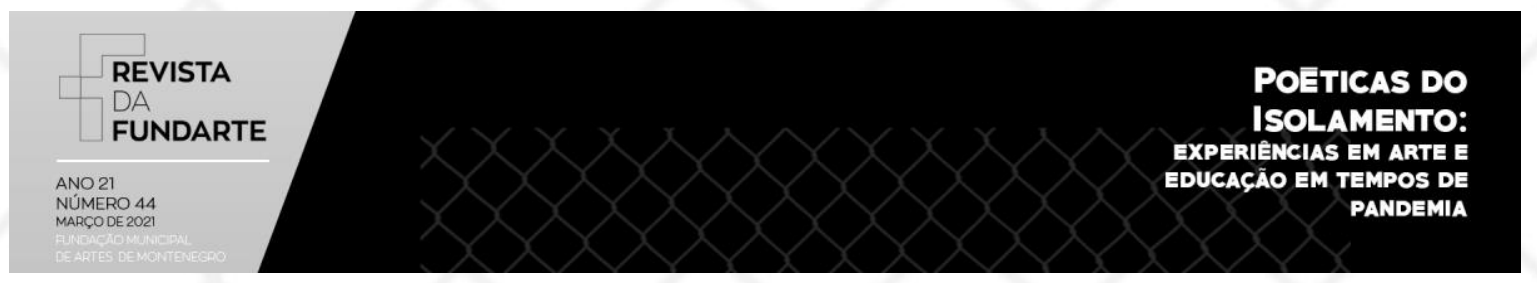

perde seu caráter assustador. Esse processo de trabalhar com o fantasma, dando vida e concretude a ele, é conhecido também na literatura infantil. Podemos lembrar, com Artur, da turma do Penadinho, uma das criações de Maurício de Sousa. A figura criada em 1963 ganhou uma série própria de gibis, em que o fantasma, o Fantasminha, e mais tarde Penadinho, vive num cemitério com um grupo de monstros, como vampiro, lobisomem, múmia e Frankenstein. O objetivo de trabalhar com esse mundo em princípio assustador é, segundo Maurício de Sousa, "para desmitificar os medos e pavores que cercaram a nossa infância, ou ainda cercam a infância de milhares de crianças em vastas áreas deste país."7 Assim, o fantasma de Artur tem uma conexão de história com o Penadinho, de Mauricio de Sousa.

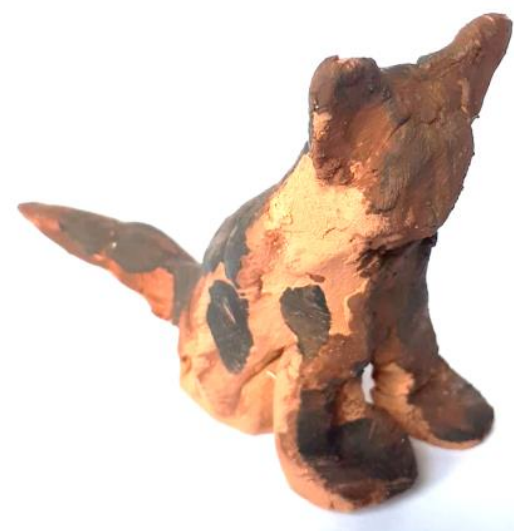

Figura 7 - O gato (Fonte: autores)

A terceira figura em argila é um gato sentado. Artur tem uma gata de quem gosta muito, e ela ganhou ainda mais importância como companheira da quarentena. Mas a figura, numa boa anatomia de um gato sentado, não coincide com a sua gata, que tem outras cores. Nessa situação, Artur modela um

\footnotetext{
${ }^{7}$ Entrevista da PUCRJ com Mauricio de Sousa. Disponível em: <https://www.deusnogibi.com.br/textos-de-apoio/dona-morte/>. Acesso em: 2 fev. 2021.
} adolescente. Revista da FUNDARTE. Montenegro, p.01-18, ano 21, o 44, janeiro/março de 2021.

Disponível em: http://.seer.fundarte.rs.gov.br/index.php/revistadafundarte/index> 30 de março de 2021. 


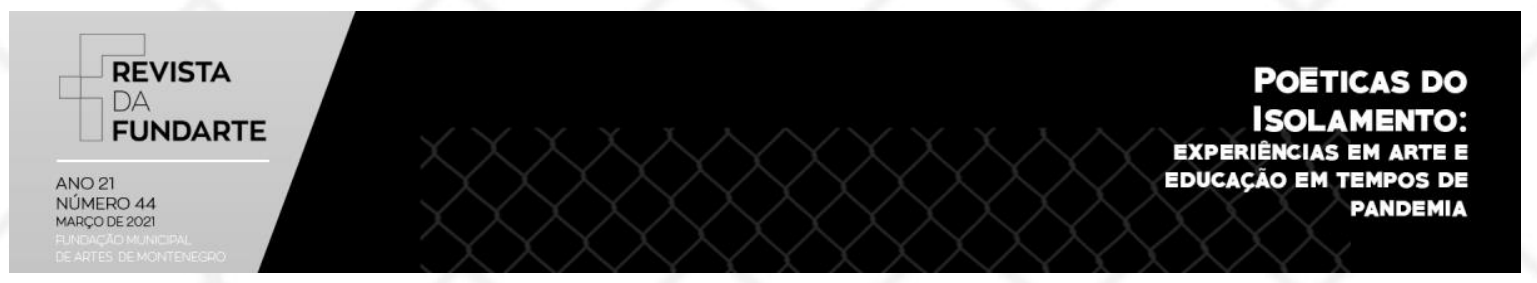

companheiro, um amigo para sua gata em quarentena. $O$ processo dessa construção lembra a bola Wilson no filme Naufrago, dirigido por Robert Zemeckis (2000), amigo imaginário de Chuck Noland (Tom Hanks) e que se torna o companheiro nos anos de solidão naquela ilha. Apesar de se tratar de um objeto, a presença de Wilson e a possibilidade de falar com ele consegue manter a saúde mental do protagonista.

A modelagem com argila é um processo de criação a partir de terra, de algo amorfo, para chegar em objetos de utilidade, em figuras que antes não existiam. Não por acaso, a criação do mundo e do homem é, em muitos mitos de origem, feita por meio de um ato do criador junto ao barro, à argila. Mas não é só a possibilidade de formar, é um dar forma com as mãos de forma direta, com contato físico, sem a necessidade de um instrumento intermediário, o que torna a relação entre criador e criado tão íntima. A expressão "colocar a mão na massa" lembra esse contato direto e também a vontade de fazer, de criar, de tomar iniciativa, de dar vida.

Os temas em argila deram forma aos medos difusos, como o alien e o fantasma, e também possibilitaram a criação de um companheiro felino para sua gata. Do ponto de vista da escola, trabalhos com argila parecem ser atividades das artes plásticas, mas não se restringem a isso. Podem ser pensadas atividades com argila nas áreas da História (reproduzir tábuas de argila para escrever, uma das mais antigas formas de escrita), na Biologia (criar impressões em argila de fósseis) ou na Geografia (criar relevos); atividades que podem ser um bom pretexto para uma conversa em sala de aula.

O terceiro campo de produções foi a escrita de pequenas crônicas. Uma tarefa clássica das aulas de Português - inventar o final de uma história iniciada; no caso, sobre dois cachorros - fez Artur se lembrar de sua gata. Incentivado pela mãe, ele inventou pequenas histórias contadas pela gata em suas dificuldades de quarentena. O retorno positivo dado pela professora e pela família estimulou Artur a continuar nessa criação, chegando ao final de 2020 com mais de trinta crônicas escritas. Todas são contadas a partir dos olhos da gata, que recebeu um nome adolescente. Revista da FUNDARTE. Montenegro, p.01-18, ano 21, no 44, janeiro/março de 2021.

Disponível em: http://.seer.fundarte.rs.gov.br/index.php/revistadafundarte/index> 30 de março de 2021. 


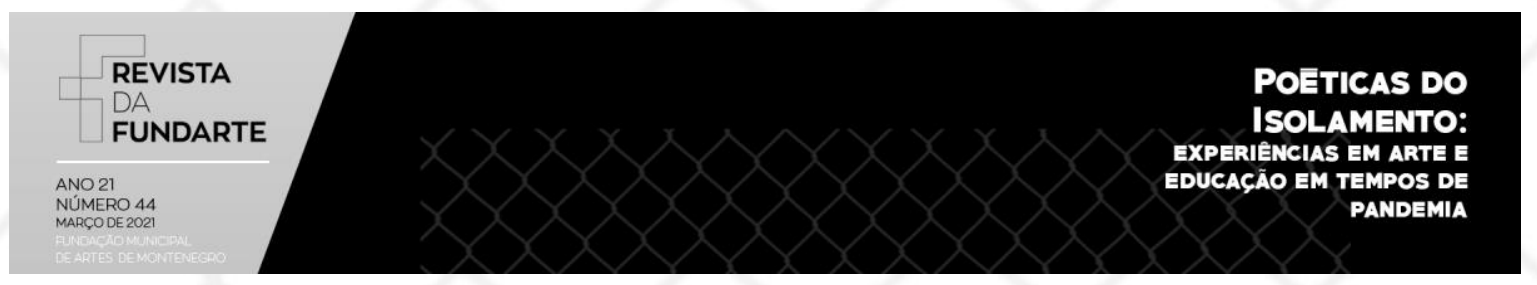

ficcional. É interessante pensar nessa dupla quebra de perspectiva, que significa uma dupla máscara para Artur: primeiramente, a máscara da gata que conta a história, e depois a própria gata coloca uma máscara trocando seu nome. Assim protegido, as histórias podem ser contatas de forma mais segura. O que aparece nessas histórias? São intercalações de pequenos eventos cotidianos acontecidos na vida em casa, com os comentários feitos pela gata, numa variedade de situações, muitas delas parecidas com a que Artur vivenciou.

Artur segue produzindo. As crônicas estão aumentando em número e em qualidade de dizer. E como advertimos no início de nosso artigo, esse é um quase estudo de caso, incompleto, uma história que ainda não terminou.

\section{Conclusão}

Para dar seguimento a seu processo de subjetivação, Artur se valeu dos elementos do cotidiano de uma casa, deu vida a produções que imprimiram sua assinatura, esculpiu corpos, fez deslizar os significantes que o representam para o mundo, deu vida/forma a seu imaginário e construiu uma sustentação simbólica em sua passagem adolescente. Para inventar sua narrativa, os adolescentes precisam dar conta da história que os engendrou. Nas crônicas de Artur, sua gata passa pelas maiores dificuldades (quer pular o muro, passa por uma castração etc.), e para falar do momento presente (isolamento na praia), Artur recorre à história pregressa da personagem, advertindo o leitor de que para entender o presente, armar o futuro, é preciso voltar no tempo, encontrar as marcas fundantes. Assim, a disponibilidade lúdica de um(a) professor(a)-artista, docente que não é nem do campo da arte, nem da psicanálise, é uma posição de leitura que compartilha o efeito da produção sobre ele, que narra, sem pudores, como se sentiu afetado pelo que olhou/escutou/leu, que compartilha as memórias evocadas e demonstra curiosidade pela sua produção. Que o humano do professor se encontre com o humano do aluno. Isso é aprendizagem! É acolhimento em tempos de pandemia e isolamento social. É dar adolescente. Revista da FUNDARTE. Montenegro, p.01-18, ano 21, № 44, janeiro/março de 2021.

Disponível em: http://.seer.fundarte.rs.gov.br/index.php/revistadafundarte/index> 30 de março de 2021. 


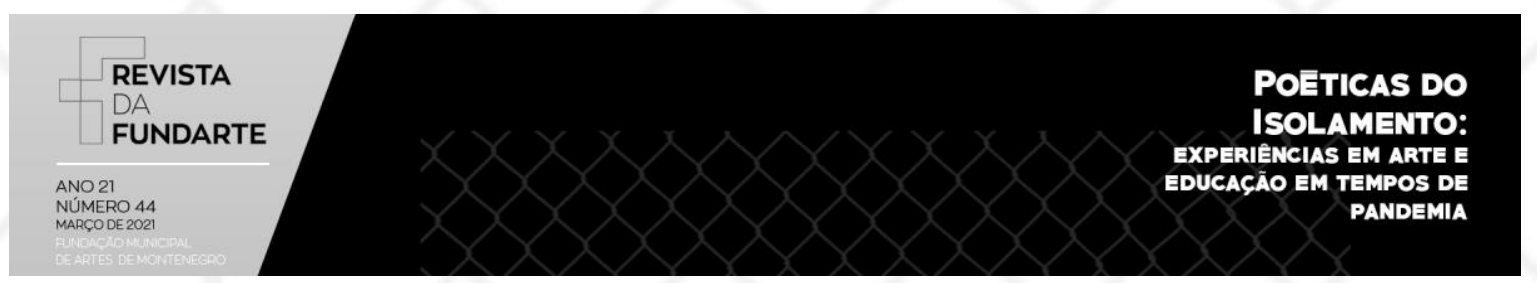

condições, não somente para o adolescente se subjetivar em situações tão adversas, mas é chance ímpar também ao adulto (família e docentes) para (re)encontrar algo de si.

\section{Referências:}

CORSO, Diana; CORSO, Mário. Adolescência em cartaz: filmes e psicanálise para entendêla. Porto Alegre: Artmed, 2018.

CONY, Carlos Heitor. Quase memória: quase romance. São Paulo: Companhia das Letras: 1995.

EISERMANN, Gottfried. Maske und Rolle. Tübingen: Mohr, 1991.

FREUD, Sigmund. (1908 [1907]). Escritores criativos e devaneios. In: . Edição standard brasileira das obras psicológicas completas de Sigmund Freud, v. IX. Rio de Janeiro: Imago, 1976. p. 147-158.

HUIZINGA, Johan. (1938). Homo ludens. São Paulo: Perspectiva, 2000.

LACAN, Jacques. (1959-1960). O seminário, livro 7: A ética da psicanálise. Rio de Janeiro: Jorge Zahar, 1997.

MARSILLAC, Ana Lúcia. Aberturas utópicas: arte, política e psicanálise. Curitiba: Appris, 2018.

PALACIO, Raquel J. Extraordinário. Rio de Janeiro: Intrínseca, 2017.

RODULFO, Ricardo. O brincar e o significante: um estudo psicanalítico sobre a constituição precoce. Porto Alegre: Artes Médicas, 1990.

RUISINGER, M.M. Die Pestarztmaske im Deutschen Medizinhistorischen Museum Ingolstadt. N.T.M., n. 28, 2020, p. 235-252.

SANTA ROZA, Eliza. Quando brincar é dizer: a experiência psicanalítica na infância. Rio de Janeiro: Relume-Dumará, 1993. adolescente. Revista da FUNDARTE. Montenegro, p.01-18, ano 21, no 44, janeiro/março de 2021.

Disponível em: http://.seer.fundarte.rs.gov.br/index.php/revistadafundarte/index> 30 de março de 2021. 